\title{
POTASSIUM NUTRITION IN THE OIL PALM: A MOLECULAR PERSPECTIVE
}

\author{
MOHD NAQIUDDIN*; NYUK LING MA** and MEILINA ONG-ABDULLAH*
}

\begin{abstract}
Potassium $\left(\mathrm{K}^{+}\right)$is a major nutrient essential for plant growth and development. Acquisition of this vital element and maintenance of $\mathrm{K}^{+}$homeostasis are complex processes, facilitated by an array of membrane transporters including carriers and channels. Key mediators of $\mathrm{K}^{+}$uptake are the $\underline{K}^{+} \underline{\text { Transporters }}(\mathrm{KT}) / \underline{K}^{+}$

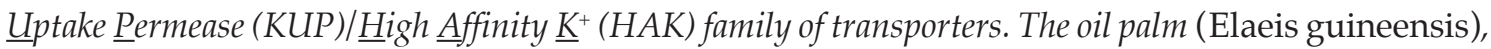
is an agriculturally and economically important crop, but the molecular mechanisms of nutrient acquisition in this plant are poorly understood. Here we report the first molecular characterisation of potassium transporters from KT/KUP/HAK superfamily in the oil palm, named EgKUP3, EgKUP8 and EgKUP11.
\end{abstract}

Keywords: potassium, KT/KUP/HAK, oil palm, molecular characterisation.

Date received: 23 January 2019; Sent for revision: 24 January 2019; Accepted: 2 October 2019.

\section{INTRODUCTION}

Elaeis guineensis or the oil palm is by far the most productive oil bearing crop (Kushairi et al., 2019; Bourgis et al., 2011; Yan, 2017), produces almost 70 million tonnes of palm oil in 2017 or $30 \%$ out of the total world edible oil production, claiming the top spot amongst 16 other vegetable oils as the most consumed oil worldwide. The global demand for oils and fats has seen a staggering increase of $167 \%$ in less than three decades from 83.5 million tonnes in 1991-92 to 223 million tonnes in 2017 (Mielke, 2017) and is expected to continue rising proportionally with the growing world population. Malaysia is the second largest producer of palm oil after Indonesia, and both countries currently account for $85 \%$ of the total palm oil production in the world (Yan, 2017). In order to meet the growing demand for oils and fats, expansion of the current 5.8 million hectares of plantation area in Malaysia is not a viable option, thus optimising the existing land to

\footnotetext{
* Malaysian Palm Oil Board, 6 Persiaran Institusi, Bandar Baru Bangi, 43000 Kajang, Selangor, Malaysia. E-mail: naqi@mpob.gov.my

** School of Fundamental Science, Universiti Malaysia Terengganu, 21030 Kuala Terengganu, Terengganu, Malaysia.
}

produce maximum yield is the only alternative for sustainable palm oil production. One of the key areas to improve productivity is mineral nutrition.

Potassium $\left(\mathrm{K}^{+}\right)$is one of the most important mineral nutrients which play diverse roles in plants daily survival including enzymatic functions, opening and closing of stomata in the leaf (to allow water vapour and waste gases to escape and at the same time to provide plants with the ability to withstand drought conditions), maintaining the turgor pressure of the cell (meaning it keeps plants from wilting) as well as regulation of cell size (Maathuis et al., 1996; Schachtman and Schroeder, 1994; Very and Sentenac, 2003). In the oil palm, $\mathrm{K}^{+}$ is a crucial element in fertilisation, which directly affects bunch weight and bunch number (Lamade et al., 2014). For this reason, palms exposed to $\mathrm{K}^{+}$deficiency have been reported to produce significantly less oil (Diomande et al., 2004). $\mathrm{K}^{+}$is also involved in the transport of sugar assimilates or 'food' from photosynthetic tissues to other parts of the plant (Lamade et al., 2014) such as inflorescence and developing fruits. $\mathrm{K}^{+}$deficiency has been associated with the occurrence of vascular wilt disease, cercospora leaf spot, Ganoderma basal stem rot, and the physiological disorders which cause bunch and plant failure (Rankine and Fairhust, 1999). 
In many plantations, the availability of $\mathrm{K}^{+}$often is very low (Maathuis, 2009), and to compensate the shortage of $\mathrm{K}^{+}$and other nutrients in soil, large amount of fertilisers are applied. Approximately $0.52 \mathrm{t} \mathrm{ha}^{-1} \mathrm{yr}^{-1}$ is required for $\mathrm{K}$ fertilisers alone with an associated cost of approximately USD $185 \mathrm{t}^{-1}$. The use of fertilisers can contribute up to $50 \%$ of the total production cost especially in time of weakened Malaysian ringgit (MYR). Besides that, with the growing concern of the deteriorating environment, there has been a drive towards mitigating the use of chemical fertilisers. Hence, palms with enhanced traits are the future planting materials for a more sustainable oil palm industry.

Development of crop less dependent on fertilisers and optimisation of fertilisation has been impeded by current lack of knowledge in the molecular aspects of agriculturally and economically important plants. Nevertheless, advances in molecular genetics and genomics in recent years such as the publication of the Elaeis guineensis genome in 2013 has provided us with endless opportunities for genomic-driven crop improvement. Moving towards this goal we looked at a few gene candidates responsible for $\mathrm{K}^{+}$uptake, specifically from the superfamily of $\underline{\mathrm{K}}^{+}$ Transporters $/ \underline{K}^{+}$Uptake $\underline{\text { Permease/High }}$ Affinity $\underline{\mathrm{K}}^{+}(\mathrm{KT} / \mathrm{KUP} / \mathrm{HAK})$ transporters. These groups of transporters are found in bacteria, fungi and plants. In plants, the transporters can be grouped into four distinct clusters (I-IV). Members of cluster I play a key role in $\mathrm{K}^{+}$acquisition particularly when $\mathrm{K}^{+}$availability is low (Banuelos, 2002; RodriguezNavarro, 2006) and are likely to function as $\mathrm{H}^{+}-\mathrm{K}^{+}$ co-transporter (Rodríguez-Navarro, 2000). Members of cluster II are involved in diverse physiological functions such as complementing the role of $\mathrm{K}^{+}$channels for low-affinity $\mathrm{K}^{+}$-transport, response to salinity and regulation of cell size (Grabov, 2007), while transporters in cluster III and IV are still not well characterised.

The objective of this study was to identify and characterise KT / KUP / HAK potassium transporters from the oil palm (EgKUP). This was achieved by obtaining: (i) full-length sequences of EgKUP using a combination of homology screening from several plant databases and Rapid Amplification of cDNA Ends (RACE), (ii) phylogenetic analyses of the obtained sequences, (iii) genes expression analysis, and (iv) functional characterisation in the heterologous system, Escherichia coli.

\section{MATERIALS AND METHODS}

\section{Plant Growth, Total Ribonucleic Acid (RNA) Extraction and cDNA Synthesis}

The Elaeis guineensis plantlets of three-month old were grown in modified-MS liquid media under
$12 \mathrm{hr}$ light (2000 lux) and $12 \mathrm{hr}$ dark cycles, and 60\% humidity prior to the experiment. Approximately $100 \mathrm{mg}$ of root tissues were disrupted using a tissue lyser. RNA was immediately extracted from the disrupted tissues using the RNeasy extraction kit (Qiagen) according to the manufacturer's protocol. The RNA obtained was then used as templates for cDNA synthesis using the Omniscript Reverse Transcription kit (Qiagen) according to the manufacturer's protocol.

\section{Construction of Full-length cDNA of the Candidate Genes}

Few gene sequences of the KT/KUP/HAK family of potassium transporters from other plant species such as Oryza sativa, Arabidopsis thaliana and Phoenix dactylifera were used as a reference to generate gene specific oligonucleotide primers for EgKUP. The construction of full-length EgKUP cDNA was then performed using SMARTer RACE cDNA Amplification Kit (Clontech) according to the manufacturer's protocol.

\section{Phylogenetic Analysis of EgKUP}

The full-length EgKUP sequences were queried against Arabidopsis thaliana databases (www. arabidopsis.org), identified and named based on the closest homologues from $A$. thaliana. Sequences of other known KT/KUP/HAK transporters from different species were downloaded from their respective database websites including rice (http:/ / crep.ncpgr.cn/crep-cgi/home.pl), maize (http:// www.maizesequence.org/index.html), tomato (http:/ / chibba.agtec.uga.edu/duplication/), wheat and barley (from NCBI database). Alignment of all the sequences was conducted using Clustal Omega (https: / / www.ebi.ac.uk/Tools/msa/clustalo/), and the subsequent phylogenetic tree was built using MEGA5 software, and the Neighbour-Joining method (Tamura et al., 2011). Bootstrap testing was performed with 1000 resampling.

\section{Gene Expression Analysis}

The plantlets were transferred into modified MS media containing three different concentrations of $\mathrm{KNO}_{3}$ namely $0.2,10$ and $20 \mathrm{mM} \mathrm{KNO}$ for periods of up to 21 days. The $\mathrm{pH}$ of the media was adjusted to 5.7 using $\mathrm{Ca}(\mathrm{OH})_{2}$ prior to use. For each $\mathrm{K}^{+}$ concentration, roots tissues were harvested at 7, 14 and 21 days of growth from experimental and control media. For each test condition $100 \mathrm{mg}$ of ground root/leaf tissues were used for RNA extraction. The RNA extraction was conducted as described. The cDNA synthesis as previously described was then performed, followed by quantitative realtime polymerase chain reaction (PCR) using the Quantitect SYBR Green RT-PCR kit in $0.2 \mathrm{ml}$ thin- 
walled PCR tubes (Qiagen) in a final volume of $10 \mu \mathrm{l}$. The PCR signals obtained for the target transcripts were normalised against the signal obtained for GAPDH (oligonucleotide primer sequences) are given in Table 1 and the expression levels were then compared to the control group using the method described by Livak and Schmitten (2001).

\section{Growth Test Assay}

The full-length of EgKUP3, EgKUP8 and EgKUP11 were individually cloned into plasmid pBAD24 (oligonucleotide primer sequences) are given in Table 1 and then transformed into the Escherichia coli strain TKW4205, deficient in all $\mathrm{K}^{+}$uptake systems. For bacterial growth tests, at low $\mathrm{K}^{+}$, serial dilution drops of strains grown in LB supplemented with $30 \mathrm{mM} \mathrm{K} \mathrm{K}^{+}$were inoculated on a solid medium containing $5 \mathrm{mM} \mathrm{PO}_{4} \mathrm{H}_{3} 0.4$ $\mathrm{mM} \mathrm{MgSO} 4^{\prime} 6 \mu \mathrm{M} \mathrm{FeSO}{ }_{4^{\prime}} 1 \mathrm{mM}$ citric acid, $1 \mathrm{mg}$ litre $^{-1}$ thiamine, $0.2 \%$ glycerol, $8 \mathrm{mM}$ asparagine, 20 $\mu \mathrm{M} \mathrm{Ca}{ }_{2} \mathrm{Cl}$, and oligo-elements brought to $\mathrm{pH} 5.5$ or $\mathrm{pH} 7.5$ with $\mathrm{HCl}$ or arginine respectively and supplemented with $13 \mathrm{mM}$ arabinose and either 50-, 5- or $1 \mathrm{mM} \mathrm{K}^{+}$concentrations. This medium is based on that described by Senn et al. (2001). The petri dishes were then incubated at $37^{\circ} \mathrm{C}$ for $48 \mathrm{hr}$. The assay was performed to evaluate whether the defect of E. coli TKW4205 can be substantially corrected by the introduction of a plasmid harbouring EgKUP genes.

\section{RESULTS AND DISCUSSION}

\section{Identification of the Oil Palm KT/KUP/HAK Transporters}

In order to understand the molecular basis of $\mathrm{K}^{+}$ uptake and homeostasis, it is essential to obtain the genes encoding $\mathrm{K}^{+}$transporters from E. guineensis. The combination of homology screening from several plant databases such as rice, Arabidopsis, date palm and oil palm itself, total RNA extraction, RACE and PCR techniques had successfully led to the identification of three full-length genes from the $\mathrm{KT} / \mathrm{KUP} / \mathrm{HAK}$ family named EgKUP3, EgKUP8 and EgKUP11. The full-length sequences were subjected to phylogenetic analysis together with their counterparts from other species for conformity. Results from the analysis confirmed that all EgKUP belong to the KT/KUP/HAK family of membrane transporters. EgKUP3 and EgKUP8 are grouped under cluster II, while EgKUP11 is in cluster III (Figure 1).

\section{Regulation of EgKUP at Gene and Protein Levels}

To further characterise $E g K U P$, we conducted quantitative real time-PCR (qRT-PCR) to evaluate the gene expression level following $\mathrm{K}^{+}$-starvation of the oil palm plantlets. Level of expression for EgKUP3 and EgKUP11 remained unaffected by $\mathrm{K}^{+}$-starvation treatment, whereas for EgKUP8, the expression was markedly increased by seven- and five-fold respectively at 14- and 21-day of treatment (Figure 2). This result triggers the question on whether some of the cluster II transporters are also involved in high-affinity transport. To investigate whether the changes of EgKUP8 observed at the gene level is translated at the protein level, we conducted functional complementation assay by cloning the full-length of EgKUP8 into Escherichia coli knockout strain defective in $\mathrm{K}^{+}$uptake systems. The cells harbouring EgKUP8 were able to complement the cells' defect at $50 \mathrm{mM}$ and $5 \mathrm{mM}$ but not at the lowest $\mathrm{K}^{+}$-concentration, $1 \mathrm{mM}$, when tested at $\mathrm{pH}$ 7.5. At low $\mathrm{pH}$ ( $\mathrm{pH}$ 5.5), only positive control cells were able to survive. Based on previous studies, high-affinity transporters have certain distinct

TABLE 1. OLIGONUCLEOTIDE PRIMER SEQUENCE for (A) QUANTITATIVE REAL-TIME POLYMERASE CHAIN REACTION (qRT-PCR) EXPERIMENT AND (B) CONSTRUCTION OF pBAD24 PLASMIDS CONTAINING EgKUP

\begin{tabular}{|c|c|c|c|}
\hline & Primer identification & Sense primer $\left(5^{\prime}-3^{\prime}\right)$ & Antisense primer $\left(5^{\prime}-3^{\prime}\right)$ \\
\hline \multirow[t]{4}{*}{ A } & EgKUP3_qrt & GCCAAGTTCATTCAGATGG & ССТСАСТACСAGCСTTGAGC \\
\hline & EgKUP8_qrt & GCATCGTCCGCTATGGATAC & CACCATGCCATTGGGTTC \\
\hline & EgKUP11_qrt & TGTATGGCAATTGGAGATGG & GACCACAGCAACAAGTACAACC \\
\hline & GADPH_qrt & GAGAGAGCGTGCTACTCATCTT & CGGAAGTGCTTCTGAGATCC \\
\hline \multirow[t]{7}{*}{ B } & EgKUP3-pBAD & GGGCCCGAATTCATGGATCA & GGGCCCCCATGGCTA \\
\hline & & GGAGAGAGGGATGCA & CATAGTAGATCATA \\
\hline & & & СССАСТТСАА \\
\hline & EgKUP8-pBAD & GGGCCCCCATGGATGGATCT & GGGCCCAAGCTTTCA \\
\hline & & CGAGGGCGGT & GACATGGTAAATCATCCCC \\
\hline & EgKUP11-pBAD & GGGCCСTCTAGAATGGCATC & GGGCCCAAGCTTCTATACAT \\
\hline & & GGAGACGG & AGAATATCTGTCCСАСАТTCA \\
\hline
\end{tabular}

Note: Fonts in bold indicate restriction enzyme sequences. 


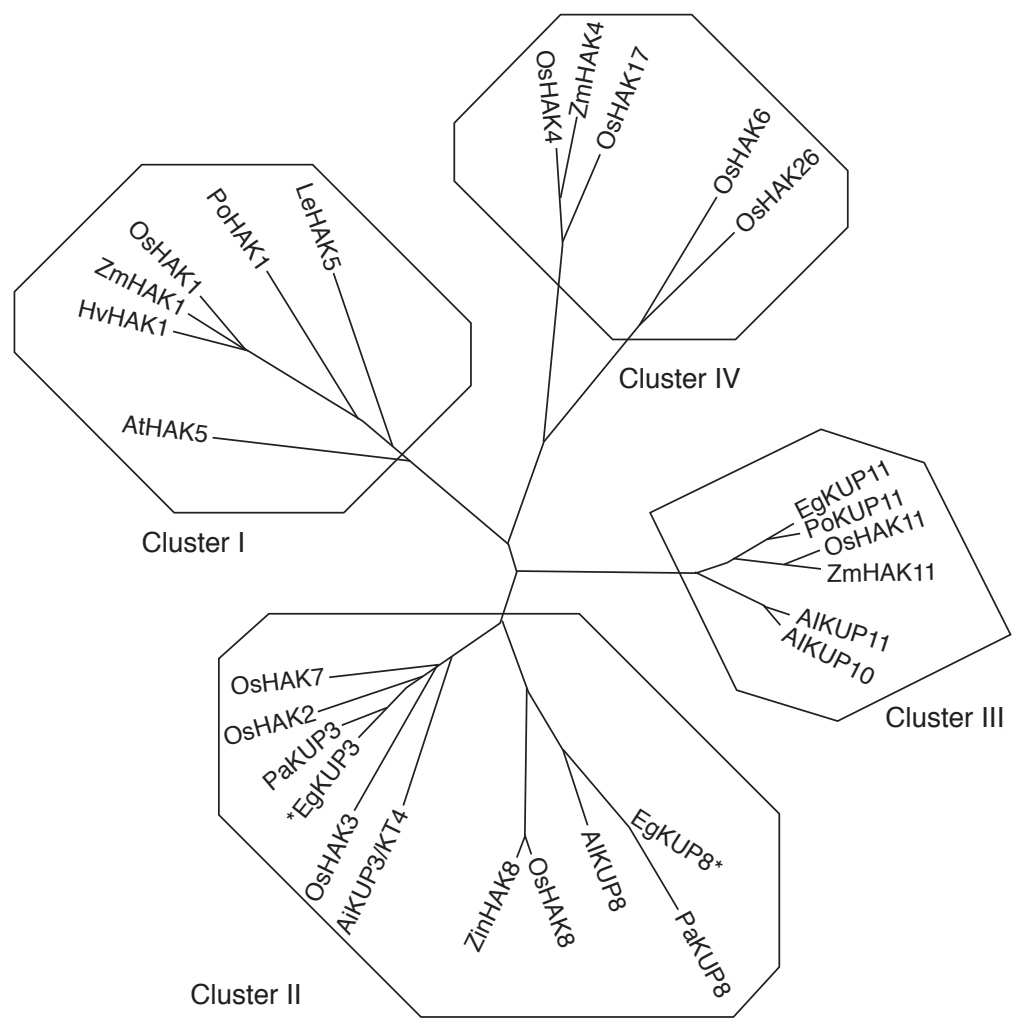

Figure 1. Phylogenetic relationship between representatives of KT/KUP/HAK family in several plant species including Oryza sativa (Os), Zea mays $(\mathrm{Zm})$, Phoenix dactylifera $(P d)$, lycopersicon esculentum (Le) and Hordeum vulgare (Hv). EgKUP are indicated by asterisks.

characteristics including (i) upregulation of gene level under $\mathrm{K}^{+}$deprivation (under $1 \mathrm{mM} \mathrm{K}^{+}$), and (ii) complement growth of $\mathrm{K}^{+}$deficient cells under low $\mathrm{K}^{+}(1 \mathrm{mM}$ and lower) and low $\mathrm{pH}$ ( $\mathrm{pH}$ 5.5).

The fact that EgKUP8 does not fulfil the second criteria may indicate that this transporter is not energised by inwardly directed $\mathrm{H}^{+}$gradients or in other words it may not function as high-affinity $\mathrm{H}^{+}-\mathrm{K}^{+}$co-transporter, at least when recombinantly expressed in E. coli. A very similar expression profile was reported for another cluster II transporter, AtKUP3, with expression was strongly upregulated by $\mathrm{K}^{+}$starvation $(40 \mu \mathrm{M})$ in Arabidopsis seedlings, but failed to mediate high-affinity transport when expressed heterologously in E. coli (Kim et al., 1998). The result, however, should not be treated as conclusive before further investigation takes place. Perhaps, EgKUP8 needs some 'adjustment' to function at lower $\mathrm{K}^{+}$concentration and low $\mathrm{pH}$ when expressed in prokaryotic system. This systemdependent behaviour has been demonstrated for the AtHAK5 of A. thaliana. In planta the AtHAK5 mediates high-affinity transport, however only after the introduction of a point mutation, F130S, that the transporter was able to function as high-affinity transporter (at $100 \mu \mathrm{M} \mathrm{K}^{+}$) in E. coli (Alemán et al., 2014). Nevertheless, the results from expression and functional complementation assays may indicate the importance of EgKUP8 in $\mathrm{K}^{+}$-sufficient environment with low-affinity mode of transport.
On the other hand, the expression of EgKUP3 and EgKUP11 was not affected by changes in environmental $\mathrm{K}^{+}$conditions. At protein level, EgKUP3 and EgKUP11 demonstrated $\mathrm{K}^{+}$transport function only at $50 \mathrm{mM}$ external $\mathrm{K}^{+}$concentration when tested at pH7.5. These observations may suggest that primary function of EgKUP3 and EgKUP11 may not be in $\mathrm{K}^{+}$transport.

\section{CONCLUSION}

This study provides insights into the oil palm potassium uptake at molecular level. Three membrane transporter candidates from the KT/KUP/HAK family, EgKUP3, 8 and 11, have successfully been identified and cloned. All of the transporters demonstrated $\mathrm{K}^{+}$transport function based on the functional complementation assay. Taking together results from the gene expression study, it is clear that none of the EgKUP transporters reported here fulfill the criteria of being a highaffinity transporter. However, the observation that EgKUP8 is transcriptionally activated in plants at $\mathrm{K}^{+}$-deficiency may indicate its importance for $\mathrm{K}^{+}$ uptake in $\mathrm{K}^{+}$-sufficient environment, because such activation may compensate for low efficiency of these transporters in sub-mM concentrations. The study serves as a foundation for further molecular physiology research in understanding the precise 

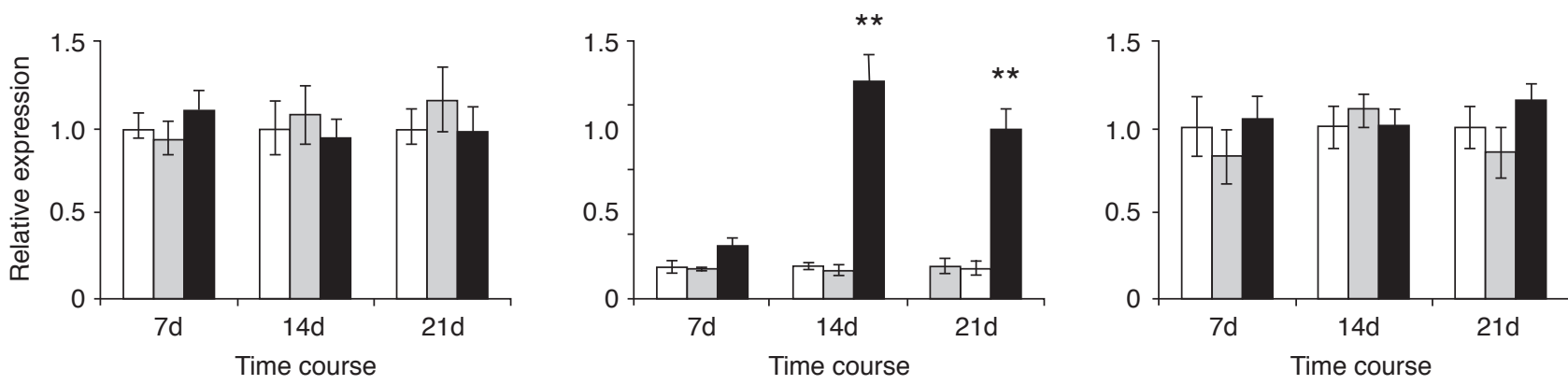

Control

Excess-K+

Depleted-K+

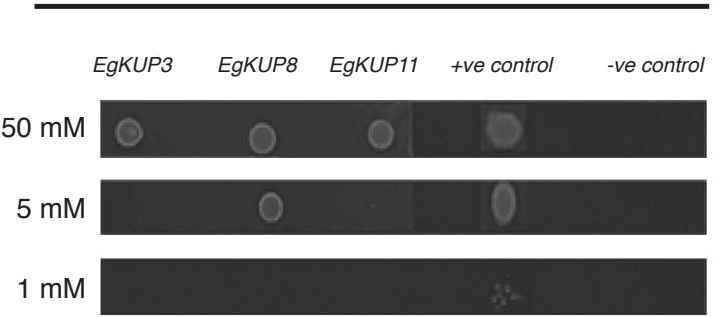

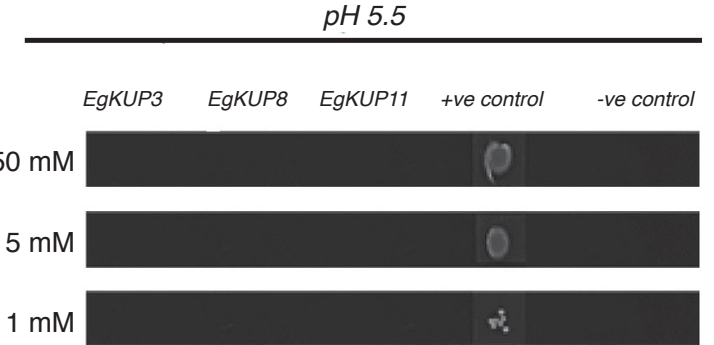

Figure 2. Regulation of EgKUP3, 8, and 11 at gene and protein level. (a) Gene expression of EgKUP in three-month old oil palm plantlets following incubation at different $\mathrm{K}^{+}$concentrations. The graphs show the expression of EgKUP3, 8 and 11 in root tissues following excess $\mathrm{K}^{+}$treatment (20 mM $\left.\mathrm{K}^{+}\right)$and depleted $\mathrm{K}+$ treatment $(0.2 \mathrm{mM} \mathrm{K})$ compared to control group $\left(10 \mathrm{mM} \mathrm{K} \mathrm{K}^{+}\right)$at 7-, 14- and 21-day after treatment. Data points are the average of three experiments carried out in triplicate. Statistical analysis was performed using a student's $t$-test comparing high and low concentration $\mathrm{K}^{+}$ samples with the control; ${ }^{* *}$ represents $p<0.01$. (b) EgKUP mediated bacterial growth at three different external $\mathrm{K}^{+}$concentrations; $50 \mathrm{mM}, 5 \mathrm{mM}$ and $1 \mathrm{mM}$ of $\mathrm{K}+$, tested at $\mathrm{pH} 7.5$ and $\mathrm{pH}$ 5.5. The negative control was TKW4205 cells containing empty vector while the positive control was BL21 cells also containing empty vector.

mechanism of nutrient acquisition in oil palm. The growing knowledge in this area will greatly assist us in designing planting materials with improved nutrient efficiency.

\section{ACKNOWLEDGEMENT}

The authors would like to express their gratitude to the Director-General of MPOB for permission to publish this article. We are also grateful to Prof Bernadette Byrne of the Imperial College, London, United Kingdom for her supervision on this project.

\section{REFERENCES}

Alemán, F; Caballero, F; Ródenas, R; Rivero, R M; Martínez, V and Rubio, F (2014). The F130S point mutation in the Arabidopsis high-affinity $\mathrm{K}(+)$ transporter AtHAK5 increases $\mathrm{K}(+)$ over $\mathrm{Na}(+)$ and $\mathrm{Cs}(+)$ selectivity and confers $\mathrm{Na}(+)$ and $\mathrm{Cs}(+)$ tolerance to yeast under heterologous expression. Frontiers in Plant Science, 5: 430-430. DOI: 10.3389/ fpls.2014.00430.

Banuelos, M A (2002). Inventory and functional characterization of the HAK potassium transporters of rice. Plant Physiology, 130(2): 784-795.

Bourgis, F; Kilaru, A; Cao, X; Ngando-Ebongue, G F; Drira, N; Ohlrogge, J B and Arondel, V (2011). Comparative transcriptome and metabolite analysis of oil palm and date palm mesocarp that differ dramatically in carbon partitioning. Proc. of the National Academy of Sciences USA, 108(30): 12527-12532.

Diomande, K; Ballo, K; Konate, A; Adohi-Krou, A; Soro, P A and Ebby, N (2004). Application of laser induced fluorescence technique to the study of potassium deficiency of the palm oil tree [Elaeis guineensis (Jacq)]. Agronomie Africaine, 13(3): 95-106. 
Grabov, A (2007). Plant KT/KUP/HAK potassium transporters: Single family - multiple functions. Annals of Botany, 99(6): 1035-1041.

Kim, E J; Kwak, J M; Uozumi, N and Schroeder, J I (1998). AtKUP1: An Arabidopsis gene encoding high-affinity potassium transport activity. Plant Cell, 10(1): 51-62.

Kushairi, A; Meilina Ong-Abdullah; Balu Nambiappan; Elina Hishamuddin; Mohd Noor Izuddin Zanal Bidin; Razmah Ghazali; Vijaya Subramaniam; Shamala Sundram and Ghulam Kadir Ahmad Parveez (2019). Oil palm economic performance in Malaysia and R\&D progress in 2018. J. Oil Palm Res. Vol. 31(2): 165-194.

Lamade, E; Ollivier, J; Rozier-Abouab, $\mathrm{T}$ and Gérardeaux, E (2014). Occurrence of potassium location in oil palm tissues with reserve sugars: Consequences for oil palm $\mathrm{K}$ status determination. Paper presented at the International Oil Palm Conference, Bali, Indonesia. Paper without proceedings retrieved from http://agritrop.cirad. fr/574656/

Livak, K J and Schmittgen, T D (2001). Analysis of relative gene expression data using real-time quantitative PCR and the 2[-Delta Delta C(T)] method. Methods, 25(4): 402-408. DOI: 10.1006/ meth.2001.1262.

Maathuis, F; Verlin, D; Smith, F A; Sanders, D; Fernandez, J A and Walker, N A (1996). The physiological relevance of $\mathrm{Na}+-$ coupled $\mathrm{K}+-$ transport. Plant Physiol., 112(4): 1609-1616.

Maathuis, F J M (2009). Physiological functions of mineral macronutrients. Current Opinion in Plant Biology, 12(3): 250-258.
Mielke, T (2017). Global Oil Supply, Demand and Price Outlook with Special Emphasis on Palm Oil. 44 pp.

Rankine, I and Fairhust, T H (1999). Management of phosphorus, potassium and magnesium in mature oil palm. Better Crops International, 13(1): 10-15.

Rodriguez-Navarro, A (2006). High-affinity potassium and sodium transport systems in plants. J. Experimental Botany, 57(5): 1149-1160.

Rodríguez-Navarro, A (2000). Potassium transport in fungi and plants. Biochimica et Biophysica Acta (BBA) - Reviews on Biomembranes, 1469(1): 1-30.

Schachtman, D P and Schroeder, J I (1994). Structure and transport mechanism of a high-affinity potassium uptake transporter from higher plants. Nature, 370(6491): 655-658.

Senn, M E; Rubio, F; Banuelos, M A and RodriguezNavarro, A (2001). Comparative functional features of plant potassium HvHAK1 and HvHAK2 transporters. J. Biol. Chem., 276(48): 44563-44569. DOI: $10.1074 /$ jbc.M108129200.

Tamura, K; Peterson, D; Peterson, N; Stecher, G; Nei, M and Kumar, S (2011). MEGA5: Molecular evolutionary genetics analysis using maximum likelihood, evolutionary distance, and maximum parsimony methods. Molecular Biology and Evolution, 28(10): 2731-2739. DOI: 10.1093/ molbev/msr121.

Very, A A and Sentenac, H (2003). Molecular mechanisms and regulation of $\mathrm{K}+$ transport in higher plants. Annu. Rev. Plant Biol., 54: 575-603.

Yan, W (2017). A makeover for the world's most hated crop. Nature, 543(7645): 306-308. 